\title{
CONCENTRATED TRAINING OF STUDENTS \\ IN THE HOLISTIC COMPUTER AUDIENCES OF UNIFIED ELECTRONIC INFORMATION AND EDUCATION ENVIRONMENT OF A PEDAGOGICAL UNIVERSITY
}

(C) 2017

Bogoslovskiy Vladimir Igorevich, doctor of pedagogical sciences, professor,

head of Preparation and Certification of Frames of Top Skills Department, professor of Information and Technological Education Technologies Department

Herzen State Pedagogical University of Russia (Saint Petersburg, Russian Federation)

Aniskin Vladimir Nikolaevich, candidate of pedagogical sciences, associate professor, dean of Mathematics, Physics and Computer Science Faculty,

associate professor of Computer Science, Applied Mathematics and Methods of Their Teaching Department

Gorbatov Sergey Vasilievich, candidate of pedagogical sciences,

associate professor of Computer Science, Applied Mathematics and Methods of Their Teaching Department

Dobudko Alexandr Valerianovich, candidate of pedagogical sciences,

associate professor of Computer Science, Applied Mathematics and Methods of Their Teaching Department

Dobudko Tatiana Valerianovna, doctor of pedagogical sciences, professor,

head of Computer Science, Applied Mathematics and Methods of Their Teaching Department

Samara State University of Social Sciences and Education (Samara, Russian Federation)

Abstract. The paper is devoted to the technology of the concentrated training in unified information and education environment (UIEE) that helps to achieve a synergetic effect and a systematic emergence in the teaching and educational process and increases university students' proficiency level. The authors analyze the purpose, tasks and advantages of UIEE concept development in the Russian Federation. They say that the information and education holizm of defines the structure of the holistic information and education environment. The authors define ways of increasing a didactic potential of computer audiences due to their holistic configuration, which is carried out by various functions of the traditional technical means of training, modern and perspective electronic and communicative means, systems and technologies of training and educational and research means.

Keywords: UIEE; technology of concentrated training; immersion method; traditional technical means of training; modern and perspective electronic and communicative means; educational and research means; holism; synergy; emergence; information and education holism; holistic information and education environment; holistic configuration of computer audiences; university students' proficiency level.

\section{МОДЕЛЬ РАЗВИТИЯ ТВОРЧЕСКОГО ПОТЕНЦИАЛА ПРЕПОДАВАТЕЛЯ ТЕХНИЧЕСКОГО ВУЗА}

Буренина Валентина Игоревна, старший преподаватель

кафедры юриспруденции, интеллектуальной собственности и судебной экспертизы

Московский государственный технический университет имени Н.Э. Баумана

(г. Москва, Российская Федерация)

Кочетова Наталья Геннадьевна, кандидат физико-математических наук, доцент, декан факультета начального образования

Самарский государственный соџиально-педагогический университет (2. Самара, Российская Федераџия)

Аннотация. В статье отмечается необходимость и выявлена специфика развития творческого потенциала преподавателя технического вуза. Представлен анализ последних исследований и публикаций в данной области, а также сформулирована необходимость специального исследования данного вопроса. Предложенная модель развития творческого потенциала преподавателя технического вуза состоит из целевого, содержательно-технологического и диагностического блоков. В работе приводятся характеристики разработанной модели, описывается каждый ее компонент. Целевой блок включает ожидаемые образовательные результаты. Содержательно-технологический блок состоит из следующих структурных компонентов: внешние условия, содержание образования и используемые технологии, а также формы организации образовательного процесса. В компонент «Внешние условия» входят психологическая защищенность и возможности для самовыражения и самореализации. В компонент «Содержание образования» включены как объекты изучения все компоненты творческого потенциала. Компонент «Используемые технологии и формы организации образовательного процесса» учитывает закономерности деятельностного подхода в образовании с использованием активной деятельности обучающихся, симулирующих профессиональную деятельность преподавателя технического вуза: деловые и интеллектуальные игры, проектные задания и т.п. Диагностический блок отслеживает и корректирует результаты внедрения модели. В него включены критерии и показатели сформированности каждого компонента творческого потенциала, описание уровней развития творческого потенциала преподавателя технического вуза. 
Ключевые слова: творческий потенциал; ФГОС ВО; профессиональный стандарт педагога; развитие творческого потенциала преподавателя технического вуза; модель развития творческого потенциала; условия развития творческого потенциала; содержание образования; технологии и формы организации образовательного процесса.

Творческое развитие личности заявлено как один их важных векторов деятельности образовательной системы в Национальной доктрине образования РФ (2000-2025 гг.). Поскольку необходимым звеном между образовательной системой и личностью является преподаватель, именно его профессиональная реализация как творческой личности становится залогом формирование творческого потенциала обучающихся.

Вместе с тем в ФГОС ВО развитию творческого потенциала уделяется недостаточно внимания; идеи формирования профессиональных компетенций преподавателя технического вуза фактически не сформулированы, хотя заявленные тенденции к усилению научно-исследовательской подготовки студентов, междисциплинарности и интегративности в потенциале позволяют усилить творческую составляющую высшего образования. В профессиональном стандарте педагога указано на необходимость «расширения пространства педагогического творчества» и раскрепощения педагога, однако и в этом документе идеи развития творческого потенциала преподавателя скорее задекларированы, чем развиты, а компетенции описываются достаточно фрагментарно.

Сказанное выше детерминирует необходимость обновления профессионального педагогического образования в направлении формирования творческого мышления педагога, активизации собственной креативности и умения развивать творческие способности обучающихся, то есть формирования творческого потенциала.

В диссертационном поле отечественной педагогики наличествует ряд работ, посвященных анализу учебного процесса вуза [1-4]. Вопросы развития творческих способностей и творческого потенциала педагога, в том числе, преподавателя высшей школы поднимаются в ряде классических и новаторских работ по педагогике: В.А. Гусева, Т.А. Дроновой, Е.А. Ефимовой, А.Л. Бусыгиной, С.И. Разуваева, Е.О. Галицких и др. [5-11]. В то же время этот процесс не конкретизирован для преподавателя технического вуза, а он, как показало наше исследование имеет свою специфику, а значит, требует специального подхода.

Анализ определений творческого потенциала, приведенных в исследованиях Н.В. Мартишиной, В.Г. Рындак, Н.А. Степаненко и др. [12-14], позволил нам трактовать эту категорию как постоянно развивающуюся систему ресурсов, резервов и возможностей саморазвития и самореализации преподавателя в профессиональной сфере. Ее свойствами являются интегративность, динамичность и направленность. Система имеет сложную, многоуровневую структуру и в качестве компонентов включает личностные характеристики, способности, психологические установки, знания и умения, приобретенный профессиональный опыт. Творческий потенциал преподавателя технического вуза имеет свою специфику, выражающуюся в интеграции научно-технических $[15 ; 16]$ и педагогических знаний, способностей и способов действий. Эта специфика наиболее ярко проявляется в когнитивно-деятельностном компоненте творческого потенциала, который представлен в табл. 1.

таблица 1 - Когнитивно-деятельностный компонент творческого потенциала преподавателя технического вуза

\begin{tabular}{|c|c|c|}
\hline & $\begin{array}{c}\text { Педагогическая } \\
\text { творческая деятельность }\end{array}$ & $\begin{array}{c}\text { Техническая } \\
\text { творческая деятельность }\end{array}$ \\
\hline $\begin{array}{c}\text { - деятельность по выдвижению } \\
\text { принципиально новых решений }\end{array}$ & $\begin{array}{l}\text { Создание новых педагогических } \\
\text { концепций, подходов. Теоретиче- } \\
\text { ские исследования в области педа- } \\
\text { гогики }\end{array}$ & $\begin{array}{l}\text { Поиск принципиально новых ре- } \\
\text { шений технических задач, выдви- } \\
\text { жение новых технических идей }\end{array}$ \\
\hline $\begin{array}{l}\text { - деятельность по детализации, } \\
\text { конкретизации, проработке этого } \\
\text { нового с целью определения } \\
\text { принципиальной возможности } \\
\text { его практической реализации }\end{array}$ & $\begin{array}{l}\text { Разработка новых технологий обу- } \\
\text { чения, реализующих педагогиче- } \\
\text { ские концепции, конкретизация } \\
\text { разработанных технологий, их } \\
\text { адаптация к преподаванию част- } \\
\text { ных дисциплин. Эмпирические ис- } \\
\text { следования в области педагогики: } \\
\text { проверка эффективности разрабо- } \\
\text { танных технологий. }\end{array}$ & $\begin{array}{l}\text { Реализация новых решений, разра- } \\
\text { ботка технических проектов, реа- } \\
\text { лизующих новые технические } \\
\text { идеи. Эмпирическое исследование: } \\
\text { испытание созданных технических } \\
\text { объектов, проверка эффективности } \\
\text { разработанных технических проек- } \\
\text { тов. }\end{array}$ \\
\hline $\begin{array}{l}\text { - деятельность по воплощению но- } \\
\text { вых идей в жизнь, их объектива- } \\
\text { ции в тех или иных материаль- } \\
\text { ных формах. }\end{array}$ & $\begin{array}{l}\text { Разработка программ новых дис- } \\
\text { циплин, фонда оценочных средств } \\
\text { для диагностики усвоения учебно- } \\
\text { го материала по дисциплине. }\end{array}$ & $\begin{array}{l}\text { Разработка технической докумен- } \\
\text { тации и материалов по популяри- } \\
\text { зации и продвижению созданных } \\
\text { технических объектов. }\end{array}$ \\
\hline
\end{tabular}

Творческий потенциал преподавателя технического вуза является сложной саморазвивающейся системой и в своем развитии проходит следующие уровни: наследование-копирование, творческое наследование, подражательное творчество, самостоятельное творчество. Уровни различаются степенью сформированности каждого компонента творческого потенциала преподавателя.

Развитие творческого потенциала преподавателя технического вуза может осуществляться при выполнении совокупности внутренних и внешних условий. В качестве внутренних условий выступают 
ресурсы, резервы и возможности личности. Внешние условия - это психологическая защищенность субъекта творчества и свобода его самовыражения. Соответственно необходимо разработать модель развития творческого потенциала преподавателя технического вуза с учетом специфики его деятельности.
На основе анализа разных подходов к развитию творческого потенциала личности [17-21] и уточнения состава творческого потенциала преподавателя технического мы разработали организационно-содержательную модель развития творческого потенциала преподавателя технического вуза (рис. 1).

\section{Целевой блок}

Цель: развитие творческого потенциала преподавателя технического вуза

\section{Содержательно-технологический блок}

Внешние условия развития творческого потенцииала

(приниипь построения модели развития творческого потенииала)

Психологическая защищенность: направленность Т Свобода самовыражения: обеспечение возможности публичных обсуждений продуктов творческой дея- $\quad$ публично представить разработанный способ решения тельности на конструктивную критику, поиск досто- $\quad$ технической и/или педагогической задачи

инств и путей дальнейшего совершенствования;

предоставление свободы выбора для выполнения

творческого задания по интересам

\begin{tabular}{|c|c|c|c|c|c|c|c|}
\hline \multicolumn{6}{|c|}{ Содержание образования (объекты изучения) } & \multirow{2}{*}{\multicolumn{2}{|c|}{$\begin{array}{c}\text { Используемые технологии } \\
\text { и формы организации } \\
\text { образовательного прочесса }\end{array}$}} \\
\hline $\begin{array}{l}\text { Предметное со- } \\
\text { держание (техни- } \\
\text { ческая область) }\end{array}$ & \multicolumn{2}{|c|}{$\begin{array}{l}\text { Педагогическое } \\
\text { содержание }\end{array}$} & \multicolumn{3}{|c|}{ Метапредметное содержание } & & \\
\hline $\begin{array}{l}\text { Способы решения } \\
\text { стандартных задач } \\
\text { разного уровня } \\
\text { сложности. } \\
\text { Теоретическая база } \\
\text { разных способов } \\
\text { решения стандарт- } \\
\text { ных и нестандарт- } \\
\text { ных задач. }\end{array}$ & \multicolumn{2}{|c|}{$\begin{array}{l}\text { Сущность разных ме- } \\
\text { тодов преподавания, } \\
\text { основных способов } \\
\text { действий в стандарт- } \\
\text { ных педагогических } \\
\text { ситуациях. } \\
\text { Методологические ос- } \\
\text { новы организации об- } \\
\text { разовательного про- } \\
\text { цесса. }\end{array}$} & \multicolumn{3}{|c|}{$\begin{array}{l}\text { Гибкость: нестандартное мыш- } \\
\text { ление: умение выдвигать гипо- } \\
\text { тезы о существовании и сущно- } \\
\text { сти других способов решения } \\
\text { задач. Способность находить не- } \\
\text { сколько способов решения тех- } \\
\text { нической или педагогической } \\
\text { задачи. } \\
\text { Оригинальность: умение нахо- } \\
\text { дить принципиально новые спо- } \\
\text { собы решения локальных техни- } \\
\text { ческих или педагогических за- } \\
\text { дач. } \\
\text { Экономичность: способность } \\
\text { находить и обосновывать способ } \\
\text { решения задачи, требующий } \\
\text { наименьших ресурсных затрат } \\
\text { Эмпатия: уровень выше средне- } \\
\text { го или высокий. }\end{array}$} & \multicolumn{2}{|c|}{$\begin{array}{l}\text { Развивающие технологии; } \\
\text { проектные и исследователь- } \\
\text { ские технологии, игровые } \\
\text { технологии (интеллектуаль- } \\
\text { ные и деловые игры), симу- } \\
\text { ляция профессиональных си- } \\
\text { туаций, психологические и } \\
\text { интеллектуальные тренинги. }\end{array}$} \\
\hline \multicolumn{8}{|c|}{ Диагностический блок (результаты образования) } \\
\hline \multicolumn{2}{|c|}{$\begin{array}{l}\text { Уровни развития творческого } \\
\text { потенциала преподавателя тех- } \\
\text { нического вуза }\end{array}$} & \multicolumn{2}{|c|}{$\begin{array}{l}\text { Наследование- } \\
\text { копирование }\end{array}$} & $\begin{array}{l}\text { Творческое } \\
\text { наследование }\end{array}$ & \multicolumn{2}{|c|}{$\begin{array}{l}\text { Подражательное } \\
\text { творчество }\end{array}$} & $\begin{array}{l}\text { Самостоятельное } \\
\text { творчество }\end{array}$ \\
\hline
\end{tabular}

Рисунок 1 - Модель развития творческого потенциала преподавателя технического вуза

Она состоит из следующих блоков: целевого, содержательно-технологического и диагностического. Каждый из названных блоков имеет свою цель и определенное содержание. В то же время блоки взаимосвязаны и взаимозависимы. Связью, объединяющей блоки в систему, являются образовательные цели, описанные в виде компонентов творческого потенциала, который понимается нами как владение профессиональными компетенциями на высоком уровне. Блоки расположены в последовательности, соответствующей структуре деятельности.

Целевой блок направлен на создание и внедрение модели развития творческого потенциала, который формулируются в виде ожидаемых образовательных результатов (знаний и способов деятельности).
Содержательно-технологический блок включает в себя три структурных компонента.

Первый компонент - это внешние условия. Творческая деятельность в составе творческого потенциала и творческий потенциал в целом формируются только в условиях психологической защищенности и наличии возможностей для самовыражения и самореализации. Психологическая защищенность обеспечивается следующими условиями:

1. Направленностью публичных обсуждений продуктов творческой деятельности на конструктивную критику. Этому способствует внедрение в практику образовательного процесса таких форм организации обучения, как групповые. Например, при подготовке к семинару обучающимся выдаются творческие задания на группу, выполнение которого предполагает 
осуществление мозгового штурма и дальнейшего представления другим группам его результатов.

Приведем пример такого задания. Представьте, что вы - преподаватели технических дисциплин в вузе. Вам нужно организовать первое заседание научного студенческого кружка с целью поиска пути решения технической задачи. В кружок входят студенты, пока еще не очень представляющие, что им нужно делать и в каком направлении двигаться. Вы должны организовать их деятельность так, чтобы они самостоятельно осознали необходимость поиска решения поставленной задачи, наличие разных способов решения сходных задач, возможность комбинации разных способов решения, нашли разные способы решения данной задачи и выбрали наиболее рациональный. Составьте беседу, направленную на получение названных образовательных результатов.

Условия выполнения задания: беседа должна быть эвристической, то есть, отвечая на вопросы преподавателя, студенты сами должны прийти к новому знанию. Преподавателю запрещено что-либо объяснять студентам.

Это задание предполагает совместное обсуждение возможных способов его выполнения. Обучающиеся в группе, выдвигая свои идеи, по сути, обучаются друг у друга (коммуникация как интериоризация), приобретая опыт творческой педагогической деятельности, причем, это обучение происходит ненавязчиво, не затрагивает амбиций обучающихся.

2. Поиском достоинств и путей дальнейшего совершенствования разработанных способов решения, новых областей их применения. Организация совместных обсуждений выполнения заданий или разработки проектов с целью дальнейшего совершенствования способов решения позволяет, с одной стороны, формировать гибкость мышления, умение видеть разные функции изучаемых объектов, с другой стороны, обучающимся испытывать удовлетворение от своей деятельности, полезность свой разработки.

3. Предоставлением свободы выбора для выполнения творческого задания по интересам. Например, на курсах повышения квалификации по изучаемым дисциплинам предлагаются комплекты заданий, дифференцируемых по видам творческой деятельности. Каждый обучающийся вправе выбрать задания, соответствующие его интересам. Или, например, проективное задание может состоять из нескольких заданий. Совместное выполнение такого задания обучающимися предполагает выбор каждым из них такого задания, которое ему наиболее интересно.

Второй компонент рассматриваемого блока - это содержание образования. В него включены как объекты изучения все компоненты творческого потенциала. Это означает, что развитие творческого потенциала должно происходить целенаправленно и осознанно. Каждый обучающийся выстраивает будущий образ своего творческого потенциала.

Данный процесс должен быть управляем. Включение в содержание образования способов действий, психологических установок и качеств личности предполагает прямое управление образовательным процессом, то есть творческий потенциал, его структура, содержание и сущность его компонентов являются объектами изучения. С этой целью мы разработали курс учебной дисциплины «Проектирование рабочих программ дисциплин и фондов оценочных средств дисциплин для образовательных программ высшего образования». Он направлен на изучение и овладение способами педагогической творческой деятельности, входящими в состав деятельностного компонента творческого потенциала преподавателя технического вуза.

Третий компонент содержательно-технологического блока имеет название «Используемые технологии и формы организации образовательного процесса». Его включение в модель учитывает закономерность Л.С. Выготского «Усвоение материала происходит только в деятельности, причем, чем активнее деятельность, тем успешнее усвоение» и реализует деятельностный подход к образованию. В качестве основных образовательных технологий используются такие, которые направлены на организацию активной деятельности обучающихся, симулирующих профессиональную деятельность преподавателя технического вуза: деловые и интеллектуальные игры, проектные и т.п.

Целью третьего, диагностического блока модели является отслеживание и корректирование результатов внедрения модели. В него включены критерии и показатели сформированности каждого компонента творческого потенциала, описание уровней развития творческого потенциала преподавателя технического вуза, диагностические материалы (тесты, портфолио, экспертные оценочные листы и т.п.), предназначенные для поуровневой оценки степени развития творческого потенциала преподавателя технического вуза.

Разработанная модель предназначена для внедрения и функционирования в образовательном пространстве курсов переподготовки и повышения квалификации преподавателей технического вуза. Ее апробация в Федеральном государственном бюджетном образовательном учреждении высшего образования «Московский государственный технический университет имени Н.Э. Баумана (национальный исследовательский университет)» позволила судить о результативности разработанной модели.

\section{СПИСОК ЛИТЕРАТУРЫ:}

1. Агрикова Е.В. Интеграция творческой письменной речи в учебный процесс по иностранному языку студентов - будущих журналистов // Иноязычное образование: традиции и инновации: мат-лы междунар. науч.-практ. конф. / ред. кол.: В.В. Левченко, Е.Г. Кашина, Л.А. Кожевникова, Е.А. Соколова. Самара: Самарский государственный университет, 2015. С. 7-14.

2. Воронина М.А., Кочетова Н.Г. Применение онлайн-ресурсов в процессе обучения иностранному языку бакалавров педагогического направления // Вестник ВГУ. Серия: проблемы высшего образования. 2017. № 1 С. 25-30.

3. Кочетова Н.Г., Котова Т.А. Оптимизация воспитательного пространства высшей школы в решении задач профессиональной подготовки бакалавров педагогического образования // Педагогика городского пространства: теория, методология, практика: сб. трудов по мат-лам всерос. науч.-практ. конф. (Самара, 25-26 марта 2015 года) / ред. кол.: Т.А. Чичканова (отв. ред.), Н.С. Искрин, О.Ю. Ко- 
зырь. Самара: ООО «Издательство АС-ГАРД», 2015. C. 321-328.

4. Цибизова Т.Ю., Терехова Н.Ю. О перспективах развития высшего образования в современных условиях // European Social Science Journal. 2013. № 2 (30). C. 62-67.

5. Гусев В.А. Профессионально-педагогическое образование в многоуровневых комплексах: дис. ... дра пед. наук. Тольятти, 2004. 352 с.

6. Дронова Т.А. Концепция формирования интегрально-креативного стиля мышления в процессе личностно-профессионального становления педагога: автореф. дис. ... д-ра пед. наук. Воронеж, 2011. $43 \mathrm{c}$.

7. Ефимова Е.А. Формирование творческой самореализации будущего педагога: автореф. дис. ... канд. пед. наук. Новокузнецк, 2007. 26 с.

8. Бусыгина А.Л. Организационно-педагогические основы инвариантной подготовки преподавателей высшей школы: дис. ... д-ра пед. наук. Тольятти, 2000. 353 c.

9. Разуваев С.И. Профессионально-творческое саморазвитие педагога в условиях инновационной деятельности учреждения начального профессионального образования: автореф. дис. ... канд. пед. наук. М., $2010.27 \mathrm{c}$.

10. Галицких Е.О. Интегративный подход как теоретическая основа профессионально-личностного становления будущего педагога в университете: автореф. дис. ... д-ра пед. наук. СПб., 2002. 43 с.

11. Буренина В.И. Формирование творческого потенциала будущего педагога в процессе становления личности [Электронный ресурс] // Современные проблемы науки и образования. 2015. № 4. http://science-education.ru/127-20938.

12. Мартишина Н.В. Становление и развитие творческого потенциала педагога в системе непрерывного педагогического образования: автореф. дис. ... д-ра пед. наук. Рязань, 2009. 43 с.
13. Рындак В.Г. Непрерывное образование и развитие творческого потенциала учителя (теория взаимодействия). М.: Педагогический вестник, 1997. 244 с.

14. Степаненко Н.А. Профессиональное самоопределение человека как начальный этап формирования конкурентоспособного специалиста // Педагогический журнал Башкортостана. 2013. № 1 (44). C. 131-137.

15. Гаврилина Е.А. Проблемы и перспективы трансформации системы высшего технического образования // Наука и образование: научное издание. 2014. № 3. C. 388-393.

16. Гаврилина Е.А. Инженерное творчество в информационном обществе: типология, динамика, критерии оценки инженерной компетентности: автореф. дис. ... канд. филос. наук. М., 2006. 23 с.

17. Берулава М.Н. Развитие творческих способностей личности в аспекте гуманизации образования // Гуманизация образования. 1998. № 1. С. 14.

18. Макаров А.С., Панфилова Л.В. Использование информационных технологий обучения по развитию творческого мышления // Методология и методы научных исследований в области естествознания: мат-лы всерос. науч.-практ. конф., посвящ. 100летию д.б.н., проф. Л.В. Воржевой. Самара: Изд-во СГПУ, 2006. С. 319-325.

19. Семенов И.Н. Рефлексивно-акмеологические проблемы развития творческого потенциала человека // Акмеология. 2009. № 3 (31). С. 20-22.

20. Семенов И.Н., Степанов С.Ю. Рефлексия в организации творческого мышления и саморазвития личности // Вопросы психологии. 1983. № 2. С. 35-42.

21. Сорокоумова Г.В. Системный подход к пониманию творческой личности педагога и механизма ее развития // Интеграция образования. № 2. Саранск: Национальный исследовательский Мордовский государственный университет им. Н.П. Огарёва, 2010. C. $90-94$.

\section{A MODEL FOR THE DEVELOPMENT OF THE CREATIVE POTENTIAL OF A TECHNICAL UNIVERSITY TEACHER}

(C) 2017

Burenina Valentina Igorevna, senior lecturer of Law, Intellectual Property and Forensic Examination Department Bauman Moscow State Technical University (Moscow, Russian Federation)

Kochetova Natalia Gennadievna, candidate of physical and mathematical sciences, associate professor, dean of Primary Education Faculty

Samara State University of Social Sciences and Education (Samara, Russian Federation)

Abstract. The article considers issues related to the development of a technical university teacher's creative potential and it's special aspects. The analysis of the latest researches and publications in this field is presented, and the necessity of a special study of this issue is formulated. A model for the development of the creative potential of a technical university teacher is proposed, which consists of target, content-technological and diagnostic blocks. The paper presents the characteristics of the model of technical university teacher's creative potential development designed by the author; each of its components is described. The target block includes educational expectations. The content-technological block consists of the following structural components: external conditions, the content of education, educational technologies and the forms of educational process organization. The component «External conditions» includes psychological resilience potential and opportunities for self-expression and self-realization. The «Content of Education» component includes all creative potential elements. The component «Educational technologies and the forms of educational process organization» consider the patterns of the activity approach in education, using students' activity which simulate the professional teachers' of a technical university activity: business and intellectual games, project tasks and etc. The diagnostic block monitors and corrects the results of the model implementation. It includes criteria and indicators of the formation of each component of creative potential, a description of the levels of development of technical university teacher's creative potential.

Keywords: Creative potential; educational standards; professional teacher's standard; development of technical university teacher's creative potential; model for development of creative potential; conditions of creative potential development; education content; educational technologies and forms of educational process organization. 